LA-UR-03- 2766

Approved for public release; distribution is unlimited.

$04 / 2512003$ c./

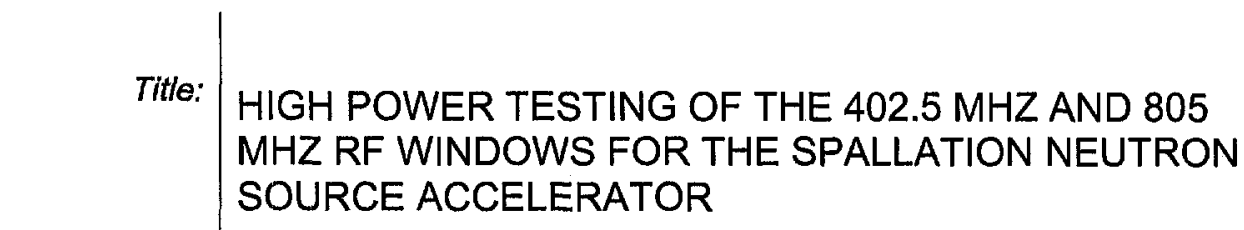

Author(s): Cummings, Karen, LANSCE-5

DeBaca, John, LANSCE-5

Harrison, John, LANSCE-5

Rodriguez, Manuelita, LANSCE-5

Torrez, Phillip, LANSCE-5

Warner, David, SNS-2

Submitted to:

IEEE 2003 PAC

Portland, OR

May 12-16. 2003

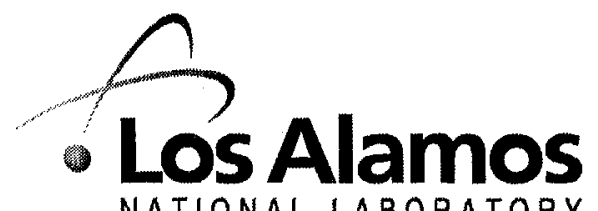

NATIONAL LABOAATORY

Los Alamos National Laboratory, an affirmative action/equal opportunity employer, is operated by the University of California for the U.S. Department of Energy under contract W-7405-ENG-36. By acceptance of this article, the publisher recognizes that the U.S. Government retains a nonexclusive, royalty-free license to publish or reproduce the published form of this cor $\equiv$ ion, or to allow others to do so, for U.S. Government purposes. Los Alamos National Laboratory requests that the publisher identify this $D$ a as work performed under the auspices of the U.S. Department of Energy. Los Alamos National Laboratory strongly supports academic freedom and a researcher's right to publish; as an institution, however, the Laboratory does not endorse the viewpoint of a publication or guarantee its technical correctness. 


\title{
HIGH POWER TESTING OF THE 402.5 MHZ AND 805 MHZ RF WINDOWS FOR THE SPALLATION NEUTRON SOURCE ACCELERATOR*
}

\author{
K.A. Cummings, J.M. De Baca, J.S. Harrison, M. Rodriguez, P.A. Torrez, D.K. Warner, \\ LANL, Los Alamos, NM 87544, USA
}

\section{Abstract}

Hisorically, Radio Frequency (RF) windows have been a common point of failure in input power couplers; therefore, reliable RF windows are critical to the success of the Spallation Neutron Source (SNS) project. The normal conducting part of the SNS accelerator requires six RF windows at $402.5 \mathrm{MHz}$ and eight RF windows at $805 \mathrm{MHz}[1]$. Each RF window will transmit up to 180 $\mathrm{kW}$ of average power and $2.5 \mathrm{MW}$ peak power at $60 \mathrm{~Hz}$ with 1.2 millisecond pulses. The RF windows, designed and manufactured by Thales, were tested at the full average power for 4 hours to ensure no problems with the high average power and then tested to an effective forward power level of $10 \mathrm{MW}$ by testing at $2.5 \mathrm{MW}$ forward power into a short and varying the phase of the standing wave. The sliding short was moved from 0 to 180 degrees to ensure no arcing or breakdown problems occur in any part of the window. This paper discusses the results of the high power testing of both the $402.5 \mathrm{MHz}$ and the $805 \mathrm{MHz}$ RF windows. Problems encountered during testing and the solutions for these problems are discussed.

\section{EXPERIMENTAL SETUP}

\section{Window Geometry}

The $402.5 \mathrm{MHz}$ and $805 \mathrm{MHz}$ windows are planar windows, shown in Figures 1 and 2, respectively. The vacuum side of both windows is copper plated stainless steel waveguide, and the air side is aluminum waveguide. The $402.5 \mathrm{MHz}$ window consists of $1 / 2$ height WR 2100 waveguide on the vacuum side and full height WR 2100 on the air side. The $805 \mathrm{MHz}$ window consists of full height WR 975 waveguide on both the air and the vacuum side. The ceramic in both windows is a high purity alumina ceramic.

Figure 1: 402.5 MHz Windows and Vacuum Waveguide.

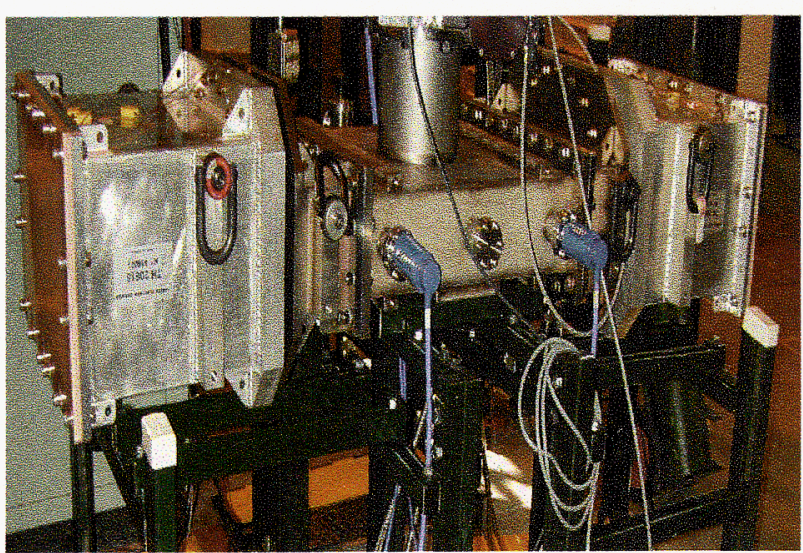

Figure 2: $805 \mathrm{MHz}$ Window Schematic.

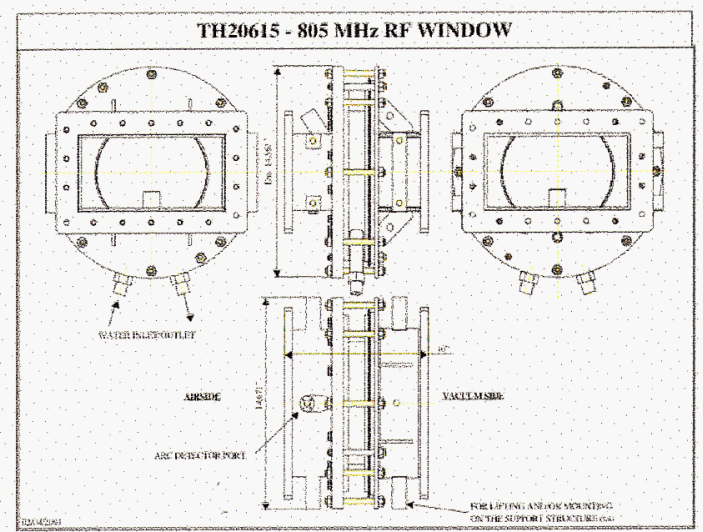

\section{Test Stand Configuration and Diagnostics}

A 2.5 MW klystron was used for the RF source[2]. Assuming waveguide and circulator losses of up to $8 \%$, $2.3 \mathrm{MW}$ of RF power was available in the test area. In a transient condition, 2.5 MW was obtained. The steady state power was $2.3 \mathrm{MW}$.

High average power testing and high peak power testing require different test configurations. In the high average power testing the forward power is transmitted through the windows into a matched load, as shown in Figure 3. The peak power setup is the same, but instead of a load a sliding short is used. The windows are tested at the full average power and duty factor for four hours and then peak power tested to an effective forward power level of $10 \mathrm{MW}$ by testing at $2.5 \mathrm{MW}$ forward power into a short and varying the phase of the standing wave. The sliding short was moved from 0 to 180 degrees to ensure no arcing or breakdown problems occur in any part of the window.

The RF power was measured with four directional couplers, as illustrated in Figure 3 . The vacuum pressure was measured with two ion gauges that are interlocked to turn off the RF power if the pressure rises above $1 \times 10^{-7}$ Torr. The water inlet and outlet temperatures and surface temperatures are also measured. Fiber optic arc detectors are used on both the air side and the vacuum side of the ceramic. If an arc is detected, an interlock turns of the RF power for 1.6 seconds. A LabVIEW data acquisition system is used to record, monitor and display the RF power, pressure, water inlet and outlet temperatures, surface temperatures and the number of arcs detected. The control racks for the test stand are shown in Figure 4. The racks are, from left to right, the $805 \mathrm{MHz}$ arc detection rack, two $805 \mathrm{MHz}$ transmitter racks, the computer rack for LabVIEW data acquisition program, a 
Figure 3: Test Schematic for Average Power Testing.

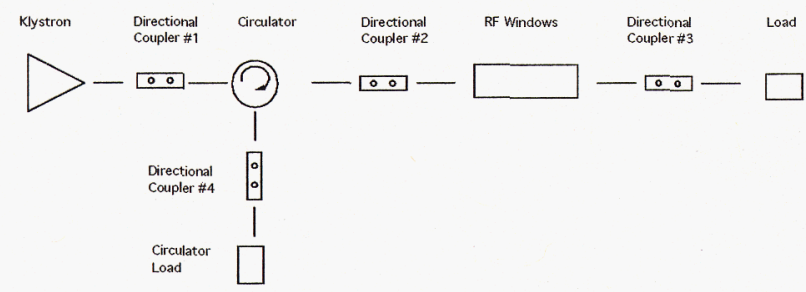

rack containing the HV ready/ crowbar interlock chassis, the ion gauges for the window vacuum, a scope displaying HV pulse waveform, pulse generator and RF signal generator, and a rack with 402.5 arc detectors, the vacuum interlocks and the gate valve controllers.

Figure 4: Control Racks for RF Window Test Stand.

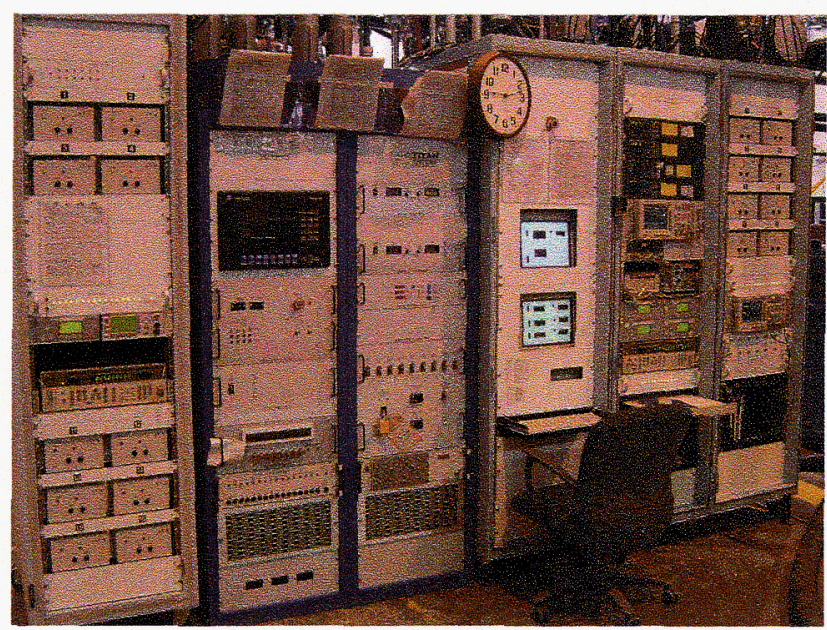

\section{EXPERIMENTAL RESULTS}

\section{High Temperature Bake Out Results}

A high temperature vacuum bake out is done to release particles and water vapor embedded in the ceramic and vacuum waveguide surfaces. During the bake out, the windows are held between $150{ }^{\circ} \mathrm{C}$ to $200{ }^{\circ} \mathrm{C}$ until the pressure drops below $5 \times 10^{-7}$ Torr as shown in Figure 5 and Figure 6. It takes 10 to 15 hours, once the windows are at the required temperature, for the vacuum level to decrease to below $5 \times 10^{-7}$ Torr. It typically takes 5 hours for the windows to reach the required temperature. Because of safety regulations, the bake out is not allowed to run unattended. The bake out requires 3 to 4 days.

The bake out is essential to conditioning the windows successfully and expediently. Testing of two unbaked $402.5 \mathrm{MHz}$ windows was attempted, but it was not successful because the vacuum pressure was too high. These two windows were then baked out and then successfully conditioned and tested. Two $402.5 \mathrm{MHz}$ windows were baked out, vented to nitrogen, exposed to air, and then re-pumped and high power tested. There was not a second bake out after the windows were exposed to air. The windows were still successfully conditioned and tested.
Figure 5: Temperature verses Time during Bake Out.

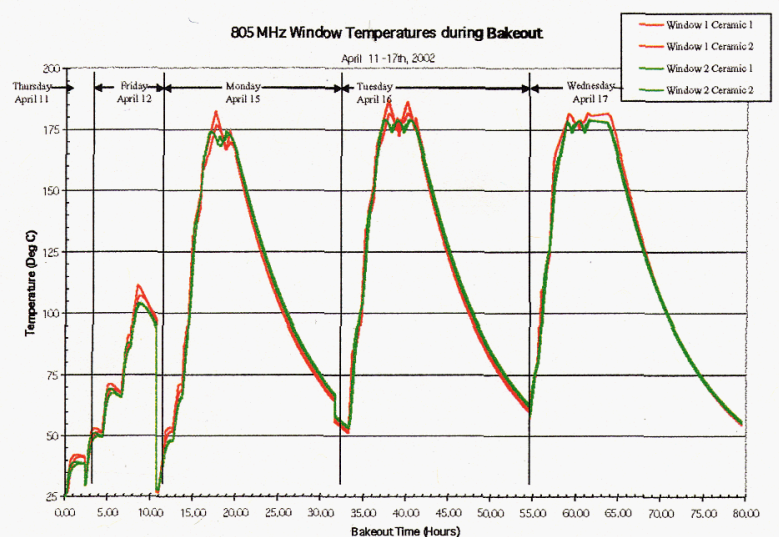

Figure 6: Pressure verses Time during Bake Out.

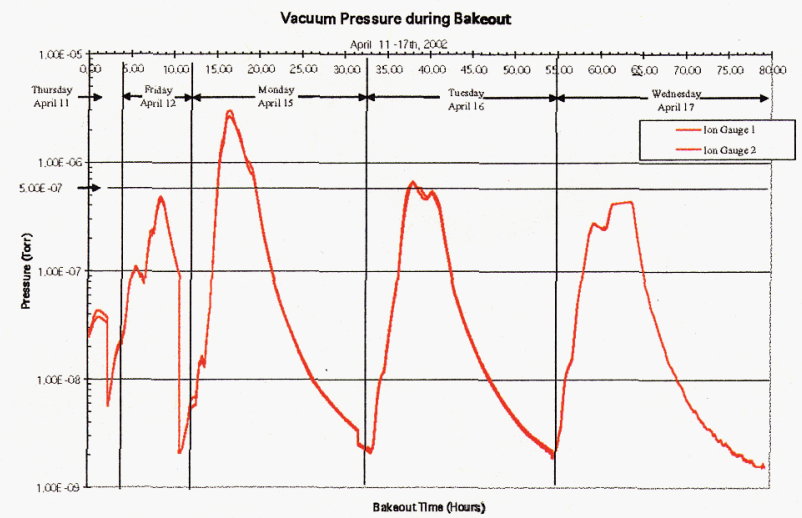

Figure 7: Windows in Heat Blankets during Bake Out.

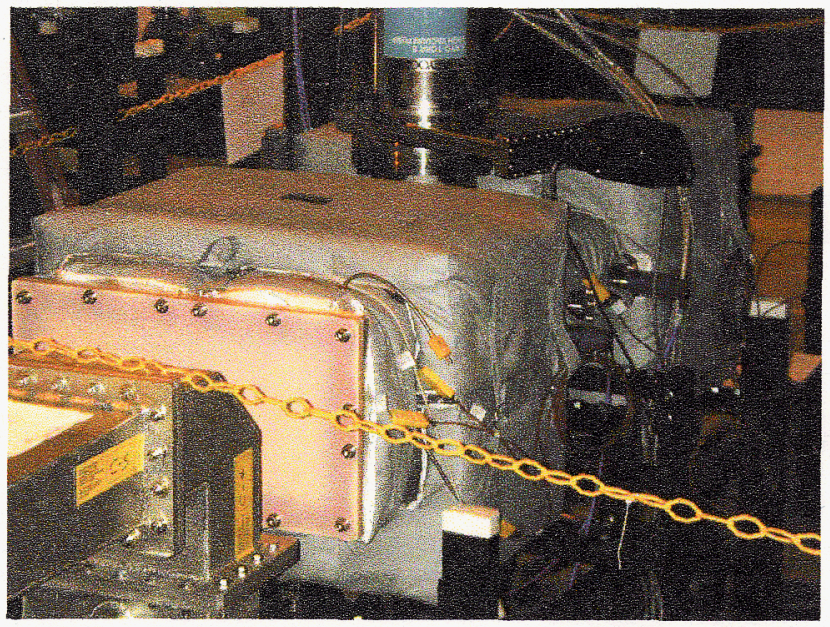

\section{High Power Test Results}

The conditioning procedure consists of beginning with a low duty factor and gradually increasing the power. Next, the power is lowered, the duty factor is increased and the power is gradually raised at the new duty factor. For the $805 \mathrm{MHz}$ windows, a graph of the peak power verses time is shown in Figure 8. Once the windows are 
conditioned, the four hour heat run is done at full power and duty factor, also illustrated in Figure 8.

It took about 10 hours to condition the $805 \mathrm{MHz}$ windows to the full power and duty factor. There were only a few arcs and the conditioning rate was limited by the pressure, as expected.

Figure 8: $805 \mathrm{MHz}$ Window Peak Power vs. Test Time.

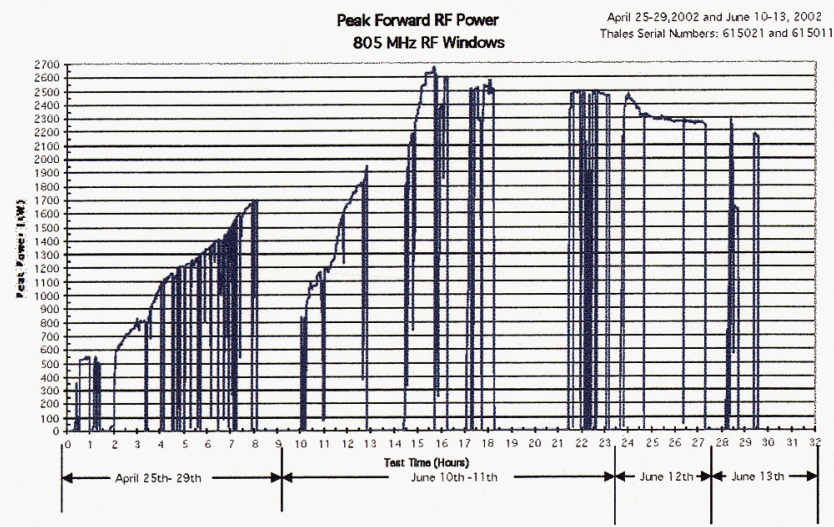

It took 5 hours to condition the first two $402.5 \mathrm{MHz}$ windows to $500 \mathrm{~kW}$. The available power supply voltage was limited, thus they were run at $500 \mathrm{~kW}$ for seven more hours. Once the full power supply capacity was available, they were conditioned up to the full power in two hours. This leads to a total conditioning time of 7 hours. The second two $402.5 \mathrm{MHz}$ windows were conditioned up to $500 \mathrm{~kW}$ in 4 hours and then once the full power supply capacity was available, they were conditioned up to full power in 3 hours. Thus, the average conditioning time for all 6 windows was 8 hours.

\section{Problems Encountered during Testing}

Two separate problems were encountered while testing the $402.5 \mathrm{MHz}$ windows. The first problem is that a RF leak was found on the top surface of the waveguide in the region of the ceramic. The leak was measured at 9.7 $\mathrm{mW} / \mathrm{cm}^{\wedge} 2$ at a distance of $10 \mathrm{~cm}$ from the surface at 6.4 $\mathrm{kW}$ average power. At $2.5 \mathrm{MW}$ peak power and $180 \mathrm{~kW}$ average power, this is extrapolated to $272 \mathrm{~mW} / \mathrm{cm}^{\wedge} 2$. This exceeded the maximum leak rate of $1 \mathrm{~mW} / \mathrm{cm}^{\wedge} 2$ at a distance of $10 \mathrm{~cm}$. This window was sent back to Thales, repaired, but has not yet been re-tested. The leak was due to an inadequate RF seal caused by loose bolts around the ceramic, as shown in Figure 9. The Thales assembly procedure was modified and additional post delivery inspections were implemented. The second problem encountered during testing is that the second pair of 402.5 $\mathrm{MHz}$ windows are arcing during the peak power test with the sliding short. This pair of windows does not arc at all when run into a matched load. When run into a sliding short both circulator and window arcs occur at the same time. This problem has not yet been resolved and it may be due to arcs in the waveguide run and/or circulator and not due to window arcs. Air will be blown through the waveguide to reduce window ares during the next window tests with the sliding short. This will help isolate the arcing problem.
Figure 9: 402.5 MHz Inner Bolt Circle.

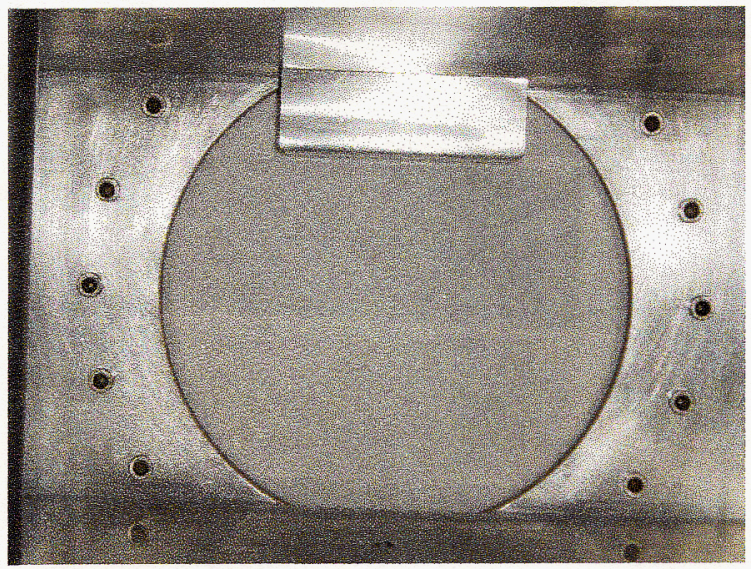

\section{CONCLUSIONS}

Two of the eight $805 \mathrm{MHz}$ windows and four of the six 402.5 MHz windows have been successfully baked out, conditioned and tested. The test results are very important because: First, they prove the design concept of the windows. Second, they have shown that the bake out is an essential part of the testing process. Windows could not be conditioned and tested with out a bake out. Third, if a window is baked and then vented to nitrogen, it retains the benefits of the bake out and does not need to be rebaked. If a window is baked, conditioned, and then vented to air, it can be reconditioned quickly[3]. Fourth, we have learned that the average conditioning time for the windows is 8 hours. It is not feasible to condition windows while conditioning the accelerator. Thus, The bake out and the conditioning of the windows on the test stand is absolutely essential to the success of the SNS project.

\section{REFERENCES}

[1] D. Rees, M. Lynch, P. Tallerico, W. Roybal, K. Cummings, T. Hardek, J. Bradley, W. Reass, A. Regan, "The RF System Design for the Spallation Neutron Source", PAC'01, Chicago, IL, 2001.

[2] D. Rees, "The SNS Linac High Power RF System Design, Status, and Results", PAC'03, Portland, OR. 2003.

[3] K. Cummings, "Theoretical Predictions and Experimental Assessments of the Performance of RF Windows", Ph.D. Dissertation, University of California, Davis, CA 1998. 